\title{
Lipoprotein Lipase Activity Determined in vivo Is Lower in Carriers of Apolipoprotein A-V Gene Variants 19W and -1131C
}

\author{
J. KOVÁŘ ${ }^{1,2}$, V. ADÁMKOVÁ1 \\ ${ }^{1}$ Institute for Clinical and Experimental Medicine, Prague, ${ }^{2}$ Centre for Cardiovascular Research, \\ Prague, Czech Republic
}

Received March 14, 2007

Accepted June 6, 2007

On-line July 26, 2007

\section{Summary}

The apolipoprotein A-V (apo A-V) plays an important role in regulation of triglyceride (TG) concentration in serum. To better understand how apo A-V affects triglyceridemia and glucoregulation, the lipoprotein lipase (LPL) activity was determined using intravenous fat tolerance test (IVFTT) and oral glucose tolerance test (oGTT) was performed in carriers of apolipoprotein A-V gene (APOAV) variants known to be associated with increased triglyceridemia. Twelve carriers of $19 \mathrm{~W}$ variant, 16 carriers of $-1131 \mathrm{C}$ variant, 1 combined heterozygote and 16 control subjects homozygous for wild type variants (19S/$1131 \mathrm{~T}$ ) were selected from a population sample and matched with respect to body mass index and age. The APOAV variants carriers had increased TG, very low density lipoprotein-TG, and apo $B$ concentrations $(p<0.05)$. The LPL activity evaluated as $k_{2}$ rate constant for clearance of Intralipid ${ }^{\circledR}$ was $14 \%$ lower in APOAV variants carriers. The depression of nonesterified fatty acids (NEFA) concentration after glucose load was delayed in $A P O A V$ variants carriers in spite of the same insulinemia and glycemia. Our results suggest that variants of APOAV combined with increased triglyceridemia are associated with lower LPL activity in vivo and with disturbances of regulation of NEFA concentration after glucose load.

\section{Key words}

Apolipoprotein A-V • Genetics • Lipoprotein lipase • Nonesterified fatty acids

\section{Corresponding author}

J. Kovár, Institute for Clinical and Experimental Medicine, Laboratory for Atherosclerosis Research, Vídeňská 1958/9, 14021 Prague 4, Czech Republic. Fax: +420 241721666. E-mail: jan.kovar@medicon.cz

\section{Introduction}

Apolipoprotein A-V (apo A-V), a recently discovered member of apolipoprotein family (Pennacchio et al. 2001, van der Vliet 2001, for review see Šeda and Šedová 2003), is a new important player in the regulation of lipoprotein metabolism. It has been suggested that this apolipoprotein is involved in the lipoprotein lipase (LPL) activation (Fruchart-Najib et al. 2004, Merkel et al. 2005) or in the control of hepatic very low density lipoprotein (VLDL) assembly and/or secretion (Weinberg et al. 2003). However, the exact mechanism of apo A-V action has not been clarified yet. Importantly, two variants of human apolipoprotein A-V gene (APOAV), -1131T/C and 19S/W, were found to be associated with increased triglyceridemia in population studies (Pennacchio et al. 2002, Hubáček et al. 2004). The same variants are more frequent among the patients with extreme hypertriglyceridemia (Hořínek et al. 2003, Vrablík et al. 2003) and it can be assumed that $-1131 \mathrm{C}$ and $19 \mathrm{~W}$ variants are dysfunctional with respect to regulation of triglyceridemia. Therefore, to better understand the role that these variants play in the regulation of lipoprotein lipase activity, the intravenous fat tolerance test (IVFTT) was carried out in both $-1131 \mathrm{C}$ and $19 \mathrm{~W}$ variant carriers and in control subjects to determine the LPL activity in vivo. Moreover, it has been shown recently that heterozygous LPL deficiency, another genetic defect associated with the development of milder forms of hypertriglyceridemia, can contribute to development of insulin resistance (Holzl et al. 2002). To determine whether these APOAV variants can affect the glucoregulation, the oral glucose tolerance test (oGTT) was carried out in the same subjects. 
Table 1. The age, body mass index (BMI) and waist-hip ratio (WHP) in control subjects and APOAV variants carriers included into the study.

\begin{tabular}{|c|c|c|c|c|c|c|}
\hline & \multicolumn{5}{|c|}{ Subjects } & \multirow[t]{3}{*}{$\mathbf{p}$} \\
\hline & \multirow[t]{2}{*}{ Controls } & \multicolumn{4}{|c|}{ Carriers of $A P O A V$ variants } & \\
\hline & & All & 19W & $-1131 C$ & $19 W /-1131 C$ & \\
\hline$n$ & 16 & 29 & 12 & 16 & 1 & \\
\hline age [years] & $52.8 \pm 10.2$ & $52.5 \pm 9.1$ & $53.7 \pm 9.4$ & $51.0 \pm 9.0$ & 61.0 & n.s. \\
\hline$B M I\left[\mathrm{~kg} / \mathrm{m}^{2}\right]$ & $28.7 \pm 2.6$ & $29.0 \pm 3.5$ & $29.8 \pm 3.2$ & $28.1 \pm 3.5$ & 33.6 & n.s. \\
\hline waist $[\mathrm{cm}]$ & $98 \pm 8$ & $96 \pm 8$ & $98 \pm 9$ & $95 \pm 8$ & 108 & n.s. \\
\hline$W H R$ & $0.93 \pm 0.05$ & $0.92 \pm 0.05$ & $0.92 \pm 0.05$ & $0.92 \pm 0.04$ & 0.95 & n.s. \\
\hline
\end{tabular}

Data are means \pm S.D. The differences between control subjects and all APOAV variants carriers were evaluated using $t$ test, the differences between three subgroups (controls, 19W, and -1131C carriers) using ANOVA. $\mathrm{p}$ - probability of differences between groups detected using ANOVA or Kruskall-Wallis statistic.

\section{Methods}

\section{Subjects and design of the study}

Subjects, carriers of $A P O A V$ variants, were selected from a $1 \%$ population sample of two districts in Czech Republic originally examined in Czech MONICA follow-up study (Cífková and Škodová 2004) in 1997 and 1998. They were invited for another examination 7 or 8 years later. The control subjects (homozygous for 19S and $-1131 \mathrm{~T}$ variants) were selected from the same population sample. They were matched to $A P O A V$ variants carriers with respect to age and body mass index (BMI) determined at the time of their examination during the population study and they did not differ in these parameters at the entry into the study (Table 1). The 19S/W and -1131T/C polymorphisms of APOAV gene and apolipoprotein $\mathrm{E}$ gene $(A P O E)$ polymorphism were determined in the above mentioned population study (Hubáček et al. 2004). Twelve carriers of $19 \mathrm{~W}$ allele (all of them heterozygous), 16 carriers of $-1131 \mathrm{C}$ allele, one subject heterozygous for $19 \mathrm{~W} /-1131 \mathrm{C}$ and 16 control subjects (homozygous for both $19 \mathrm{~S}$ and $-1131 \mathrm{~T}$ variants) were recruited. Five subjects were homozygous for $-1131 \mathrm{C}$ allele. They did not differ from heterozygous carriers in age, anthropometric parameters, lipids and lipoproteins and, therefore, homo- and heterozygous carriers of $-1131 \mathrm{C}$ allele were pooled for statistical analysis.

All subjects included into the study were examined twice. On the first occasion, they underwent clinical examination and the fasting blood for determination of lipids in serum was obtained. Oral glucose tolerance test was then carried out. At the second visit, fasting blood was obtained for isolation of lipoproteins by ultracentrifugation and intravenous fat tolerance test was carried out to determine LPL activity in vivo. The study protocol was approved by the Ethical Committee of the Institute for Clinical and Experimental Medicine and all the participants gave their informed consent.

\section{Methods}

The standard oral glucose tolerance test (oGTT) (75 g of glucose) was carried out and blood for determination of glucose, insulin and nonesterified fatty acids (NEFA) in serum was collected before and 30, 60 and $120 \mathrm{~min}$ after glucose load.

Intravenous fat tolerance test (IVFTT) was carried out as previously described (Rössner 1974) with slight modifications (Jindřichová et al. 2007). Intralipid® ( $0.1 \mathrm{~g}$ of fat $/ \mathrm{kg}$ of body weight) was injected to subjects and blood for nephelometric determination of $k_{2}$ rate constant was collected before application and then for $40 \mathrm{~min}$ after application in $5 \mathrm{~min}$ intervals. The turbidity of diluted serum was measured on MARK IV nephelometer (Scientific Furnishings LTd, England). The $\mathrm{k}_{2}$ rate constant is considered to be the measure of LPL activity in vivo.

Very low density lipoproteins (VLDL) were isolated by ultracentrifugation (Havel et al. 1955).

Cholesterol and triglycerides in serum and VLDL were determined using enzymatic kits from 
Table 2. Concentration of lipids, lipoproteins and apo $B$ in control subjects and $A P O A V$ variants carriers included into the study.

\begin{tabular}{|c|c|c|c|c|c|c|}
\hline & \multicolumn{5}{|c|}{ Subjects } & \multirow[t]{3}{*}{$\mathbf{p}$} \\
\hline & \multirow[t]{2}{*}{ Controls } & \multicolumn{4}{|c|}{ Carriers of $A P O A V$ variants } & \\
\hline & & All & $19 \mathrm{~W}$ & $-1131 C$ & $19 W /-1131 C$ & \\
\hline$n$ & 16 & 29 & 12 & 16 & 1 & \\
\hline$T G(\mathrm{mmol} / \mathrm{l})$ & $\begin{array}{c}1.57 \pm 0.68 \\
{[1.45]}\end{array}$ & $\begin{array}{c}3.29 \pm 4.09 * \\
{[1.93]}\end{array}$ & $\begin{array}{c}3.84 \pm 3.85 \\
{[2.88]}\end{array}$ & $\begin{array}{c}2.98 \pm 4.46 \\
{[1.76]}\end{array}$ & 1.89 & $<0.10$ \\
\hline cholesterol (mmol/l) & $5.62 \pm 1.01$ & $6.10 \pm 1.32$ & $6.02 \pm 1.40$ & $6.21 \pm 1.32$ & 5.29 & n.s. \\
\hline$H D L-C(\mathrm{mmol} / \mathrm{l})$ & $1.31 \pm 0.24$ & $1.28 \pm 0.39$ & $1.28 \pm 0.48$ & $1.31 \pm 0.31$ & 0.81 & n.s. \\
\hline$L D L-C(\mathrm{mmol} / \mathrm{l})$ & $3.55 \pm 0.86$ & $3.60 \pm 0.91$ & $3.33 \pm 0.89$ & $3.80 \pm 0.94$ & 3.62 & n.s. \\
\hline aро $B(g / l)$ & $1.09 \pm 0.25$ & $1.33 \pm 0.45^{*}$ & $1.45 \pm 0.64$ & $1.24 \pm 0.22$ & 1.23 & n.s. \\
\hline$V L D L-T G(\mathrm{mmol} / \mathrm{l})$ & $\begin{array}{c}1.01 \pm 0.50 \\
{[1.02]}\end{array}$ & $\begin{array}{c}2.68 \pm 5.24^{*} \\
{[1.52]}\end{array}$ & $\begin{array}{c}1.73 \pm 0.96 \\
{[1.76]}\end{array}$ & $\begin{array}{c}3.20 \pm 6.53 \\
{[1.52]}\end{array}$ & 1.89 & $<0.05$ \\
\hline$V L D L-C(\mathrm{mmol} / \mathrm{l})$ & $\begin{array}{c}0.43 \pm 0.20 \\
{[0.41]}\end{array}$ & $\begin{array}{c}0.79 \pm 1.11 \\
{[0.64]}\end{array}$ & $\begin{array}{c}0.49 \pm 0.33 \\
{[0.35]}\end{array}$ & $\begin{array}{c}0.95 \pm 1.36 \\
{[0.64]}\end{array}$ & 0.67 & $<0.10$ \\
\hline$V L D L-C / V L D L-T G$ & $0.45 \pm 0.09^{\mathrm{a}}$ & $0.36 \pm 0.10^{*}$ & $0.30 \pm 0.12^{\mathrm{b}}$ & $0.39 \pm 0.08^{\mathrm{a}, \mathrm{b}}$ & 0.35 & $<0.01$ \\
\hline
\end{tabular}

Data are means \pm S.D. [medians]. The medians are shown for variables with non Gaussian distribution. The differences between control subjects and all $A P O A V$ variants carriers were evaluated using t test except of TG, VLDL-TG, and VLDL-C concentrations when Mann-Whitney test was used. The differences between three subgroups (controls, 19W, and $-1131 \mathrm{C}$ carriers) were evaluated using ANOVA or Kruskall-Wallis statistic (TG, VLDL-TG, VLDL-C). The t test with Bonferroni correction or the Dunn's test, respectively, were used for multiple comparisons if appropriate.* - $p<0.05$ - controls vs all APOAV variants carriers. $\mathrm{p}$ - probability of differences between groups detected using ANOVA or Kruskall-Wallis statistic, ${ }^{a, b}$ - the same letters belongs to groups (controls, 19W carriers, $-1131 \mathrm{C}$ carriers) that do not differ.

Roche Diagnostics, Switzerland. High density lipoprotein-cholesterol (HDL-C) was measured after precipitation of lipoproteins containing apolipoprotein B (apo B) using enzymatic kits from the same provider and low density lipoprotein-cholesterol (LDL-C) was then calculated using Friedewald formula. Glucose concentration was determined by enzymatic kits from LACHEMA, Czech Republic, nonesterified fatty acids (NEFA) by enzymatic kits from Wako Chemicals $\mathrm{GmbH}$, Germany, and apo B was determined by kits from Orion Diagnostica, Finland.

\section{Statistics}

Depending on the data distribution, the differences between control subjects and all $A P O A V$ variants carriers were evaluated using t-test or MannWhitney test. To detect differences between controls, $19 \mathrm{~W}$ and $-1131 \mathrm{C}$ variant carriers, the ANOVA or Kruskall-Wallis statistic were used. When needed, multiple comparisons were carried out using t-test with Bonferroni correction or Dunn's test, respectively (Glantz 1992).

\section{Results}

The APOAV variants carriers had increased concentration of triglycerides, VLDL-TG, apolipoprotein $\mathrm{B}$ and had lower ratio VLDL-C/VLDL-TG than control subjects (Table 2). The statistical significance of differences in TG concentration disappeared when $A P O A V$ variants carriers were further subdivided likely due to a smaller sample size. Also, the variability of triglyceridemia was more pronounced in $A P O A V$ variants carriers - 12 out of $29 A P O A V$ variant carriers had TG concentration higher than $2 \mathrm{mmol} / \mathrm{l}$ (compared to 2 out of 16 controls), pronounced hypertriglyceridemia (TG $>4 \mathrm{mmol} / \mathrm{l}$ ) was detected in 4 carriers and none of the controls. Importantly, there were no differences between 5 homozygous and 11 heterozygous $-1131 \mathrm{C}$ allele carriers in any of analyzed parameters and therefore they were pooled for the analysis.

Remarkably, there were 4 diabetics and 13 subjects with impaired glucose tolerance among the subjects included into the study, 1 and 5 among $19 \mathrm{~W}$ variant carriers, 2 and 4 among $-1131 \mathrm{C}$ variant carriers 
Table 3. Lipoprotein lipase activity determined as $k_{2}$ rate constant in intravenous fat tolerance test, changes of glucose, insulin and NEFA concentrations during oral glucose tolerance test and HOMA index in control subjects and carriers of APOAV variants.

\begin{tabular}{|c|c|c|c|c|c|c|c|}
\hline & & \multicolumn{5}{|c|}{ Subjects } & \multirow[t]{3}{*}{$\mathbf{p}$} \\
\hline & & \multirow[t]{2}{*}{ Controls } & \multicolumn{4}{|c|}{ Carriers of $A P O A V$ variants } & \\
\hline & & & All & $19 \mathrm{~W}$ & $-1131 C$ & $19 W /-1131 C$ & \\
\hline \multicolumn{8}{|c|}{ Intravenous fat tolerance test (IVFTT) } \\
\hline $\mathrm{k} 2[\% / \mathrm{min}]$ & & $4.69 \pm 1.15$ & $3.93 \pm 1.73 *$ & $4.40 \pm 2.46$ & $3.60 \pm 1.19$ & 5.02 & $<0.10$ \\
\hline \multicolumn{8}{|c|}{ Oral glucose tolerance test (oGTT) } \\
\hline & $\begin{array}{l}\text { Time } \\
\text { [min] }\end{array}$ & & & & & & \\
\hline glucose & 0 & $5.9 \pm 1.1$ & $6.0 \pm 2.7$ & $6.7 \pm 3.8$ & $5.5 \pm 1.4$ & 5.7 & n.s. \\
\hline \multirow[t]{3}{*}[\mathrm{mmol}/\mathrm{l}]{} & 30 & $9.6 \pm 2.0$ & $10.4 \pm 3.1$ & $11.5 \pm 3.9$ & $9.7 \pm 2.3$ & 9.1 & n.s. \\
\hline & 60 & $9.0 \pm 2.0$ & $10.9 \pm 4.5$ & $12.6 \pm 4.9$ & $9.7 \pm 4.0$ & 10.7 & n.s. \\
\hline & 120 & $6.1 \pm 2.0$ & $7.3 \pm 5.1$ & $8.7 \pm 7.3$ & $6.4 \pm 2.7$ & 5.5 & n.s. \\
\hline insulin & 0 & $10 \pm 8$ & $9 \pm 5$ & $11 \pm 6$ & $7 \pm 4$ & 18 & n.s. \\
\hline \multirow[t]{3}{*}[mIU/l]{} & 30 & $62 \pm 51$ & $52 \pm 33$ & $58 \pm 41$ & $45 \pm 26$ & 77 & n.s. \\
\hline & 60 & $65 \pm 37$ & $69 \pm 53$ & $89 \pm 67$ & $49 \pm 29$ & 138 & $<0.10$ \\
\hline & 120 & $33 \pm 34$ & $32 \pm 27$ & $45 \pm 36$ & $22 \pm 13$ & 40 & n.s. \\
\hline$N E F A$ & 0 & $0.45 \pm 0.27$ & $0.53 \pm 0.28$ & $0.52 \pm 0.27$ & $0.54 \pm 0.30$ & 0.47 & n.s. \\
\hline \multirow[t]{3}{*}[\mathrm{mmol}/\mathrm{ll}]{} & 30 & $0.20 \pm 0.09^{\mathrm{a}}$ & $0.42 \pm 0.34 * *$ & $0.44 \pm 0.42^{b}$ & $0.41 \pm 0.29^{b}$ & 0.47 & $<0.01$ \\
\hline & 60 & $0.10 \pm 0.07^{\mathrm{a}}$ & $0.22 \pm 0.23^{* *}$ & $0.24 \pm 0.23^{b}$ & $0.20 \pm 0.24^{\mathrm{a}, \mathrm{b}}$ & 0.11 & $<0.05$ \\
\hline & 120 & $0.06 \pm 0.03$ & $0.13 \pm 0.19$ & $0.14 \pm 0.20$ & $0.13 \pm 0.20$ & 0.06 & n.s. \\
\hline HOMA index & & $2.72 \pm 2.48$ & $2.67 \pm 2.51$ & $3.68 \pm 3.24$ & $1.75 \pm 1.39$ & 4.48 & n.s. \\
\hline
\end{tabular}

Data are means \pm S.D. The differences between control subjects and all APOAV variants carriers were evaluated using Mann-Whitney test. Kruskall-Wallis statistic was used to detect differences between controls, $19 \mathrm{~W}$ and $-1131 \mathrm{C}$ carriers and the Dunn's test was used for multiple comparisons when appropriate. ${ }^{*}, * *-p<0.05, \mathrm{p}<0.01$, respectively - controls vs all APOAV variants carriers (MannWhitney test). $\mathrm{p}$ - probability of differences between groups detected using Kruskall-Wallis statistic, $a, b$ - the same letters belongs to groups (controls, $19 \mathrm{~W}$ carriers, $-1131 \mathrm{C}$ carriers) that do not differ.

and 1 and 4 among controls, respectively. However, none of the subjects was treated for diabetes and/or glucose intolerance at the entry into the study.

The $\mathrm{k}_{2}$ rate constant, the measure of LPL activity determined in vivo in intravenous fat tolerance test, was decreased in carriers of $A P O A V$ variants (Table 3). The difference did not remain significant when the carriers were subdivided into subgroups (19W and -1131C) $(p<0.10)$ likely because of the small size of the subgroups and due to the fact that highest $\mathrm{k}_{2}$ value in the study $\left(\mathrm{k}_{2}=10.2 \% / \mathrm{min}\right)$ was found in one of the $19 \mathrm{~W}$ allele carriers (Table 3).
There was no difference either in the course of glycemia and insulinemia or in the HOMA index between $A P O A V$ variants carriers and controls (Table 3). However, the depression of serum NEFA concentration after oral glucose load was markedly delayed in both $19 \mathrm{~W}$ and $-1131 \mathrm{C}$ allele carriers (Table 3).

\section{Discussion}

To summarize, we have found that LPL activity determined in vivo using intravenous fat tolerance test is lower in subjects carrying $19 \mathrm{~W}$ or $-1131 \mathrm{C}$ allele of $A P O A V$ 
gene than in carriers of wild type $A P O A V$ variants. Moreover, although we did not detect any differences in insulin resistance between control subjects and carriers of 19W and $-1131 \mathrm{C} A P O A V$ variants, the suppression of serum nonesterified fatty acid concentration after oral glucose administration was markedly delayed in $A P O A V$ variants carriers.

$\mathrm{Up}$ to now, the evidence that apo A-V can activate LPL has been growing up. However, the role of apo $\mathrm{A}-\mathrm{V}$ in the process is quite different than that of apo $\mathrm{C}$ II. Although the first papers on the topic were not very convincing because of supraphysiological concentrations of apo A-V (Fruchart-Najib et al. 2004, Schaap et al. 2004), there are recent data suggesting that apo A-V can facilitate interaction between VLDL, LPL and heparan sulfate at the endothelium (Merkel et al. 2005). The different role of apo A-V in LPL activation is underlined by the fact that it cannot prevent development of hyperchylomicronemia in apo C-II deficient subjects. However, up to now there has been no evidence that LPL activity is affected by apo A-V in humans. Our data obtained using IVFTT show that LPL activity is indeed lower in those carrying $A P O A V$ variants known to be associated with hypertriglyceridemia. It should be stressed that results of IVFTT reflect the LPL activity in vivo contrary to the measurement of LPL in vitro, which corresponds to the amount of active form of enzyme released into circulation by heparin. In vitro measurement cannot reflect the factors affecting LPL activity in situ such as blood flow rate and the complex interactions between all the components of the lipolytic system including LPL, VLDL, heparan sulphate, availability of apo C-II, the rate of transfer of fatty acids released from the site of hydrolysis and others.

It has been suggested that $19 \mathrm{~W}$ variant is not secreted efficiently from the liver and, therefore, may have a lower concentration in circulation (Talmud et al. 2005). Although the same authors were unable to identify any exact role for $-1131 \mathrm{C}$ variant, they pointed out that this variant is a part of more complex haplotype $A P O A V^{*} 2$. This haplotype is in linkage disequilibrium with apo C-III variant defective with respect to downregulation by insulin (Waterworth et al. 2003) - the inhibition of LPL may result from the increased apo C-III concentration in circulation. In spite of possible differences in the effect of $-1131 \mathrm{C}$ and $19 \mathrm{~W} A P O A V$ variants on metabolism of triglyceride-rich lipoproteins, we were unable to detect any differences between these $A P O A V$ variants in their effect on lipoprotein metabolism in our study.
Although there are no differences in the insulinemia and glycemia after oral glucose load between carriers of $A P O A V$ variants and control subjects, there are profound differences in the nonesterified fatty acids concentration. Concerning the mechanism of delayed suppression of NEFA concentration after oral glucose load, we do not have any data to provide an explanation. It is generally accepted that NEFA in circulation originate from lipolysis in adipose tissue, which is tightly inhibited by insulin - that was actually observed in control subjects in the study. The findings of delayed suppression of NEFA concentration after oral glucose load in $A P O A V$ variants carriers might suggest that the regulation of lipolysis in adipose tissue by insulin is defective in these subjects. Nevertheless, the mechanism of that is puzzling because we have not seen any differences in insulinemia and glycemia. If insulin action on lipolysis in adipose tissue is the same in all the subjects, it could be then speculated that higher concentration of NEFA in circulation after glucose load may rather reflect the increased leakage of fatty acids released by LPL into circulation. If this is the case, apo A-V might be involved in some way in directing fatty acids from the site of lipolysis at the endothelial surface to the tissue. It could also be speculated that, if the concentration of NEFA is higher in subjects with $A P O A V$ variants throughout the day, the VLDL production should be also increased and contribute to hypertriglyceridemia.

It should also be noted that the lower VLDLC/VLDL-TG ratio along with pronounced triglyceridemia suggest that $A P O A V$ variants carriers have on average larger VLDL particles than control subjects. Moreover, the fact that $A P O A V$ variants carriers have the same LDL-C together with increased apo B concentration implies that they have higher proportion of small dense LDL particles in circulation than the carriers of wild type alleles of $A P O A V$. Such lipoprotein profile could contribute to a higher risk of cardiovascular disease in $A P O A V$ variants carriers, but our findings need to be confirmed in other studies.

In conclusion, for the first time it has been documented that subjects carrying $19 \mathrm{~W}$ and $-1131 \mathrm{C}$ variant of $A P O A V$ gene have lower LPL activity in vivo than those having wild type $A P O A V$. The subjects carrying $19 \mathrm{~W}$ and $-1131 \mathrm{C}$ alleles were also found to have defective regulation of nonesterified fatty acid concentration after glucose load.

\section{Conflict of Interest}

There is no conflict of interest. 


\section{Acknowledgements}

The authors thank to Hana Kocandová, Irena Houšt'ková, and Dana Körberová for their excellent technical assistance. The study was supported by grant \# NR/7923-3 from IGA MH CR.

\section{References}

CÍFKOVÁ R, ŠKODOVÁ Z: Longitudinal trends in major cardiovascular disease risk factors in the Czech population. (in Czech) Čas Lék Čes 143: 219-226, 2004.

FRUCHART-NAJIB J, BAUGE E, NICULESCU LS, PHAM T, THOMAS B, ROMMENS C, MAJD Z, BREWER B, PENNACCHIO LA, FRUCHART JC: Mechanism of triglyceride lowering in mice expressing human apolipoprotein A5. Biochem Biophys Res Commun 319: 397-404, 2004.

GLANTZ SA: Primer of Biostatistics. McGraw-Hill, New York, 1992.

HAVEL RJ, EDER HA, BRAGDON JH: The distribution and chemical composition of ultracentrifugally separated lipoproteins in human serum. $J$ Clin Invest 34: 1345-1353, 1955.

HOLZL B, IGLSEDER B, SANDHOFER A, MALAIMARE L, LANG J, PAULWEBER B, SANDHOFER F: Insulin sensitivity is impaired in heterozygous carriers of lipoprotein lipase deficiency. Diabetologia 45: 378-384, 2002.

HOŘÍNEK A, VRABLÍK M, ČEŠKA R, ADÁMKOVÁ V, POLEDNE R, HUBÁČEK JA: T-1131-->C polymorphism within the apolipoprotein AV gene in hypertriglyceridemic individuals. Atherosclerosis 167: 369-370, 2003.

HUBÁČEK JA, ŠKODOVÁ Z, ADÁMKOVÁ V, LÁNSKÁ V, POLEDNE R: The influence of APOAV polymorphisms $(\mathrm{T}-1131>\mathrm{C}$ and $\mathrm{S} 19>\mathrm{W})$ on plasma triglyceride levels and risk of myocardial infarction. Clin Genet 65: 126-130, 2004.

JINDŘICHOVÁ E, KRATOCHVÍLOVÁ S, KOVÁŘ J: Glucose administration downregulates lipoprotein lipase activity in vivo: a study using repeated intravenous fat tolerance test. Physiol Res 56: 175-181, 2007.

PENNACCHIO LA, OLIVIER M, HUBACEK JA, COHEN JC, COX DR, FRUCHART JC, KRAUSS RM, RUBIN EM: An apolipoprotein influencing triglycerides in humans and mice revealed by comparative sequencing. Science 294: 169-173, 2001.

PENNACCHIO LA, OLIVIER M, HUBÁČEK JA, KRAUSS RM, RUBIN EM, COHEN JC: Two independent apolipoprotein A5 haplotypes influence human plasma triglyceride levels. Hum Mol Genet 11: 3031-3038, 2002.

MERKEL M, LOEFFLER B, KLUGER M, FABIG N, GEPPERT G, PENNACCHIO LA, LAATSCH A, HEEREN J: Apolipoprotein $\mathrm{AV}$ accelerates plasma hydrolysis of triglyceride-rich lipoproteins by interaction with proteoglycan-bound lipoprotein lipase. J Biol Chem 280: 21553-21560, 2005.

RÖSSNER S: Studies on an intravenous fat tolerance test. Methodological, experimental and clinical experiences with Intralipid. Acta Med Scand Suppl 564: 1-24, 1974.

ŠEDA O, ŠEDOVÁ L: New apolipoprotein A-V: comparative genomics meets metabolism. Physiol Res 52: 141-146, 2003.

SCHAAP FG, RENSEN PC, VOSHOL PJ, VRINS C, VAN DER VLIET HN, CHAMULEAU RA, HAVEKES LM, GROEN AK, VAN DIJK KW: ApoAV reduces plasma triglycerides by inhibiting very low density lipoproteintriglyceride (VLDL-TG) production and stimulating lipoprotein lipase-mediated VLDL-TG hydrolysis. $J$ Biol Chem 279: 27941-27947, 2004.

TALMUD PJ, PALMEN J, PUTT W, LINS L, HUMPHRIES SE: Determination of the functionality of common APOA5 polymorphisms. $J$ Biol Chem 280: 28215-28220, 2005.

VAN DER VLIET HN, SAMMELS MG, LEEGWATER AC, LEVELS JH, REITSMA PH, BOERS W, CHAMULEAU RA: Apolipoprotein A-V: a novel apolipoprotein associated with an early phase of liver regeneration. $J$ Biol Chem 276: 44512-44520, 2001.

VRABLÍK M, HOŘÍNEK A, ČEŠKA R, ADÁMKOVÁ V, POLEDNE R, HUBÁČEK JA: Ser19-->Trp polymorphism within the apolipoprotein AV gene in hypertriglyceridaemic people. J Med Genet 40: e105, 2003. 
WATERWORTH DM, TALMUD PJ, LUAN J, FLAVELL DM, BYRNE CD, HUMPHRIES SE, WAREHAM NJ: Variants in the APOC3 promoter insulin responsive element modulate insulin secretion and lipids in middleaged men. Biochim Biophys Acta 1637: 200-206, 2003.

WEINBERG RB, COOK VR, BECKSTEAD JA, MARTIN DD, GALLAGHER JW, SHELNESS GS, RYAN RO: Structure and interfacial properties of human apolipoprotein A-V. J Biol Chem 278: 34438-34444, 2003. 